\title{
Response to Critics
}

\author{
Genia Schönbaumsfeld \\ Department of Philosophy, University of Southampton, \\ Southampton, United Kingdom \\ G.M.E.Schoenbaumsfeld@soton.ac.uk
}

\begin{abstract}
In this paper I respond to the objections and comments made by Ranalli, Williams, and Moyal-Sharrock, participants in a symposium on my book on scepticism called The Illusion of Doubt.
\end{abstract}

\section{Keywords}

Cartesian picture - radical scepticism - epistemological disjunctivism - Reasons Identity Thesis - 'hinge propositions'

Before going on to discuss their individual contributions, I would like to thank Danièle Moyal-Sharrock, Chris Ranalli and Michael Williams for taking the time to engage with my work and inspiring me to think anew about some of the central topics in the book.

\section{1 \\ Response to Ranalli's “Are There Heavyweight Perceptual Reasons?”}

\subsection{Introduction}

Ranalli claims to agree with me that radical scepticism is an illusion (this issue, 117). I confess to finding this claim baffling given that he defends a Dretskean view of perceptual reasons and re-imports the very picture that I am at such pains to dispel: a conception of apparently 'factive reasons' that leave open whether what we encounter in perception is an object (or objects) located in our immediate environment or the result of massive hallucination. As I have 
extensively argued, if we allow this move, the game is over before we have even started. For this reason, I do not, as Ranalli laments, address the question whether his conception of 'factive reasons' is better than 'non-factive reasons', since his notion just constitutes another attempt to smuggle the Reasons Identity Thesis back in by another name. So, of course this conception isn't better. But that is not the view that I defend.

\section{2 'Cookie-Underdetermination'?}

Ranalli seems to accept a Dretske-type view which implies that perceptual experience can be factored into two components: the phenomenal content of the experience which is immediately present to one (Ranalli prefers to call this the information perception 'encodes', but the idea is essentially the same), plus whatever one can infer from that content: the so-called 'heavyweight implications' of what is directly present to consciousness. In other words, the overall picture is this: whatever phenomenal character my perceptual experience has underdetermines whether that experience is an experience of an actual cookie, a 'virtual cookie' or a 'hallucinated cookie'. Consequently, what I'm presented with in perceptual experience is not with a cookie, but with 'cookie-type features' from which I need to infer that a cookie is present. This is so, because, according to Ranalli, my perceptual experience leaves open the possibility that instead of an actual cookie, I am merely presented with something that looks like one, but that could be a hologram or a figment of my imagination. Such a conception immediately raises the question, of course, in what sense I am then supposed to be able to recognize that there are cookies in the jar (something that Ranalli wants to grant is possible). For if I see that there are cookies in the jar, I do not see figments of my imagination in the jar. Conversely, if I thought that I am hallucinating, I would certainly not agree that I am seeing that there are cookies in the jar. At the very least, I would qualify my claim as follows: "It looks like there are cookies in the jar, but I can't be sure."

That Ranalli wants to maintain both that one can see that there are cookies in the jar and that this doesn't rule out that one is merely hallucinating that one is, stems from his willingness to regard 'virtual cookies' and 'hallucinated cookies' as tokens of the type 'cookie'. But this is absurd. Hallucinated 'cookies' are not a type of cookie. 'Cookies' that exist only in my mind are not a kind of cookie, but merely appearances as of cookies. Neither is 'mind-independence' a property that objects have in addition to having various 'relational features' (Ranalli), just as existence is not a property that objects have in addition

1 And I don't mean the ones that sit in your browser. 
to being sweet and round, say. As Kant pointed out long ago, imaginary 100 thalers have exactly the same properties as actual 100 thalers-the real ones, contrary to the merely imagined thalers, do not have the further properties of existing and being mind-independent! Nevertheless, whether I have 100 thalers or not makes all the difference in the world (Critique of Pure Reason B627).

In other words, there are not two ways of describing a cookie: one as mind-independent and physical, the other not. Consequently, Ranalli's Mark Twain analogy fails $(107,110)$. In order to back up his claim that even if the factive reasons thesis is true, it doesn't follow that you thereby become aware of the fact that cookies are mind-independent physical objects, he gives the analogy that to claim the contrary would be to suppose that by seeing that Mark Twain is sipping tea, you'd get a reason to believe that Samuel Clemens is sipping tea, and this is false. But of course it's not like that at all. For while the names 'Mark Twain' and 'Samuel Clemens' refer to the same person, 'mind-independent cookie' and 'imagined cookie' do not constitute two different ways of referring to a cookie. For, to repeat, an imagined cookie is not a cookie, but at best the appearance of one.

To perceive that there is a cookie in the jar is not, therefore, to perceive a something which leaves it open whether I am perceiving a cookie or am merely hallucinating, and that would require a further 'perception of mind-independence' (whatever such a thing could be), in order to establish that I am perceiving an actual cookie and not a figment of my imagination. For, if I'm 'perceiving' a 'mental cookie', I'm not, of course, perceiving anything. I'm at best being appeared to in a cookie-like manner. To think otherwise, is not just to be confused about perception, but to return to what McDowell calls the Highest Common Factor conception and I call the Reasons Identity Thesis: the notion that all that perception can give us is appearance-based reasons that are compatible with appearances being massively deceptive. But that is precisely to reject the account I favour - that of knowledge-entailing, factive reasons.

Nevertheless, Ranalli wants to maintain that the 'factive reasons thesis' is compatible with Dretske's conception: "The Dretskean can grant that when you see that you have hands this gives you a reason which entails that your corresponding belief that you have hands is true whilst denying that that reason supports the heavyweight belief that ordinary objects - like hands - are not nonphysical ideas in the mind of a perceiver" (105). But if the reason that perception provides you with does not rule out that the hand in question does not exist (because it is only in your mind), one might wonder what it can so much as mean to claim that the belief that you have hands is true. Imagine that you ask your friend whether she believes that there are cookies in the jar (when 
there are), and she says 'Yes'. Further imagine you then go on to ask her, 'Do you believe that you are hallucinating?', and she says 'No'. Imagine further still that you then ask her whether she thinks that seeing that there are cookies in the jar is compatible with believing that she is hallucinating, and I'm sure she would also say 'No'. Ranalli's view, on the other hand, leads to the endorsement of 'abominable conjunctions' (DeRose 1995) such as 'I believe truly that I have hands and that I could be hallucinating that I have hands'. But one cannot, on pain of self-contradiction, believe truly that one has hands and that one is hallucinating. To believe the one excludes believing the other.

\subsection{Misconceptions about Epistemological Disjunctivism}

Ranalli thinks that epistemological disjunctivism is the view that in the good case you are in a perceptual state that furnishes you with true beliefs. This isn't quite right, however, because disjunctivists hold that good-case perception is factive in the sense that it gives you knowledge of your immediate surroundings. But there is a more pressing, albeit related, concern: Ranalli's reading of 'perceptual state'. As becomes clear in an objection that Ranalli regards as pertinent (see below), he thinks of a 'perceptual state' as a state one can be in, even though no actual perceiving is going on. And this, of course, is not disjunctivism, but a return to the 'default view'. So, unsurprisingly, on this iteration of 'disjunctivism', the view is not as good as it looks, because it is not relevantly different from the conception it opposes.

In order to ascertain whether 'factive reasons' are better than non-factive reasons, Ranalli asks us to consider the following scenario:

Instead of imagining our deceived counterpart as coming to believe P, Q, and $\mathrm{R}$ as the result of her experiences, she instead comes to believe $\sim \mathrm{P}$, $\sim \mathrm{Q}$, and $\sim \mathrm{R}$. Imagine that she's disposed to believe, upon having a pure visual hallucination as of having hands, that 'I don't have hands', or upon having a pure visual hallucination as of there being a tree in front of her, she thinks 'There's no tree there', and so on. Her beliefs would be true. Indeed, her perceptual states would be factive with respect to her corresponding negative beliefs: for, in the envatted world, having an experience as of having hands guarantees that you don't have hands, having an experience as of having a body guarantees that you don't have a body, having an experience as of there being a tree in front of you guarantees that no tree is in front of you. So, her beliefs are true, and she believes them on the basis of her factive perceptual states. (113)

So, what Ranalli is saying in this passage is that you can be in a factive perceptual state that ensures that your belief is true, even though you are massively 
deceived, because envatted - i.e., that you are either 'perceiving' nothing (or something not remotely similar to how things seem to you). But any disjunctivist would deny that such a scenario counts as an instance of good case factive perception. As I make quite clear in the book (and I am here following Pritchard 2012), the entailment thesis ('Seeing that P entails knowing that $\mathrm{P}$ ') only holds in good cases (Pritchard calls them 'good +' cases). That is to say, in cases where the environment is epistemically friendly, my cognitive faculties are operating normally and no defeaters (misleading or otherwise) are present. These conditions are clearly not satisfied in the above case, so whether or not the poor envatted brain is disposed to form beliefs that happen accidentally to be true (but are not, in fact, based on perception at all), it is not in possession of a factive perceptual reason that entails knowledge of her immediate surroundings. Consequently, the brain is not justified in believing as it does, and Ranalli's objection backfires (since he thinks disjunctivists would have to endorse the conclusion that the brain is justified).

But there is a deeper diagnosis here. Ranalli misunderstands the disjunctivist view, because he appears to think that you can be in a perceptual state even though you are massively deceived. This is precisely what disjunctivism denies. Good case perception gives you direct access to the way things are in your immediate environment and thereby provides you with factive perceptual reasons that are knowledge-entailing. In cases where one is deceived, on the other hand, one is either not perceiving anything or draws the wrong conclusion from what one perceives. In such cases one only seems to perceive that something is the case.

That Ranalli believes, by contrast, that it makes no difference to the question of whether or not one is in a perceptual state that one is actually perceiving something that is there to be perceived just shows that he is implicitly endorsing the default view and, ultimately, the Cartesian Picture as well. For, on these conceptions, one's 'subjective states' are the same, and provide one with the same 'perceptual' reasons, whether or not one has one's immediate environment in view. And such a notion is of course an heir to the Cartesian (and empiricist) contention that perception does not directly put one in touch with mind-independent objects, but only with 'ideas' that may or may not correspond to anything physical 'out there' ('without one's mind').

If so, however, it is hard to see how Ranalli thinks he can avoid radical scepticism. For, as I have shown in the book, scepticism and Cartesianism are two sides of the same coin. Consequently, if we concede to the sceptic that even in the good case we may not be 'perceiving' anything mind-independent, as good case 'perceptual' reasons are compatible, on Ranalli's view, with massive deception, then the sceptic wins. 


\subsection{Introduction}

Let's start with the positives. Williams and I agree, as he puts it, on the fundamental point: there is no scepticism without a Cartesian conception of mind and world (this issue, 141). We also agree that if we reject the Cartesian Picture, we can accept the possibility of non-inferential perceptual knowledge. Where we diverge is over the following three issues:

1. The question of whether radical scepticism is an illusion.

2. The nature and viability of epistemological disjunctivism.

3. The question of whether Wittgenstein's 'objective certainty' is a form of knowledge.

I will comment on each of these points in turn.

\subsection{Radical Scepticism and Illusion}

Williams believes that my 'theoretical diagnosis' undermines the aura of intuitiveness usually thought to sustain the radical sceptical problem, but considers charging the radical sceptic with incoherence a 'step too far' (125). Naturally, I am pleased that Williams thinks that my theoretical diagnosis suffices on its own. Nevertheless, I will say a couple of things in response to the criticisms that Williams offers of what he calls my 'therapeutic' diagnosis (the attempt to show that radical scepticism is an illusion).

Williams is right that I distinguish between 'local' and 'global' forms of the BIV hypothesis, in order to show that the former cannot get one the conclusion that perception can never be factive. But he takes issue with this idea on the grounds that the local BIV hypothesis (a recent envatment scenario) is unlike the making of quotidian perceptual errors: "Barring physical obstacles, such errors can usually be corrected by getting a better view, an option that has no counterpart in either form of the BIV case." I do not disagree, but this does not get the point of the distinction. The thought that I might recently have been envatted is not like the idea that I have made a mistake in thinking the tower round and not square. In this respect, the recent envatment scenario marks a radicalization of standard arguments from perceptual illusion and is similar to Descartes' dreaming argument (as Williams notes). Nevertheless, ordinary perceptual error and recent envatment scenarios do have something important in common: they both leave intact the idea that perception is, at least in principle, reliable (for recent envatment only threatens my own perceptual knowledge and not perceptual knowledge as such, while an appeal to perceptual error can 
only motivate scepticism if we allow that perception can sometimes be veridical). Consequently, neither argument type can establish a 'global scepticism' that contends that perception can never be factive at all (that no one has ever correctly perceived anything). But if the general veridicality of perception is not in question, we can appeal to background knowledge in order to rule recent envatment scenarios out. For although recent envatment is logically possible, it is not empirically possible and neither is there evidence of alien activity that could accomplish such a feat. Hence, if we have not already conceded the default view of perceptual reasons to the radical sceptic, neither ordinary perceptual error nor recent envatment scenarios make a 'global' BIV hypothesis compulsory. This is the point of the distinction.

Although Williams himself endorses the conclusion that I seek to establish in Chapter Three, namely that a retreat to the radically subjective ultimately serves to abolish even appearance-based knowledge (what the sceptic minimally needs to be able to salvage), he takes issue with the argument brought in to establish this contention on the grounds that it (the argument) is radically anti-Cartesian in its conception and will therefore fail to convince those who think that language is the 'vehicle of thought'. But I think the argument ought to speak even to those who believe that. For even if someone thinks that thought is prior to language and indeed a kind of language of its own, the argument has bite, as it attacks the very idea of a logically private sign. Since thinking — whatever one's views about it—is operating with meaningful signs of some kind, if Wittgenstein is right that private ostensive definition is impossible, a logically private 'thought'-language is just as impossible as any other kind of (logically) private language. The only way of avoiding this conclusion would be by way of appeal to the 'Myth of the Given', but that seems a discredited notion.

\subsection{McDowell and Wittgenstein}

Williams believes that McDowell and Wittgenstein have different sceptical targets, while attributing to me the contention that they are shooting at the same one. While I do think that global Cartesian scepticism and the Agrippan regress problem (the targets Williams believes that McDowell and Wittgenstein have in their sights, respectively) are closely related concerns (since both require as an answer the appeal to an absolute certainty of some kind), I am not exercised by the exegetical question of how similar their individual approaches to scepticism are. Rather, what I show is that Wittgenstein's discussion in On Certainty (OC) is a good fit with, and further bolsters, my critique of the Reasons Identity Thesis and the Cartesian Picture (and this does not require attributing the same views about scepticism to McDowell and Wittgenstein). 
In this respect, I also disagree with Williams' reading of disjunctivism as a substantial theoretical conception about perceptual content. Following Travis' critique of McDowell, Williams contends:

To have things in view is to see what is there to be seen, but it is not to be presented with reasons to take them to be any way in particular. What we make of what we see-what things are there and their arrangement or doings-depends on our recognitional capacities and background knowledge. Perhaps we always do, or can, make something of them, but this is never simply by virtue of our seeing them. (127)

Regardless of what McDowell's own full-blown view of perception is (and I suspect it is not what Travis makes of it), I fail to see how Williams' remark is supposed to be incompatible with the epistemological disjunctivism that I endorse which holds only that good-case perception is factive (I do not discuss the nature of perceptual content).

For why, one might wonder, if one takes the epistemology to be correct here (as Williams clearly seems to), can the fact that I see that things are thus and so not serve as my reason for believing that things are thus and so? This idea does not strike me as particularly controversial and certainly does not require thinking that perceptions are reasons or that perceptions present me with reasons (as both of these notions are confused). If, for example, someone asks me, 'Why do you think that there are three chairs in the spare room?', and I respond, 'Because I was in the room and saw that there are three chairs there', then my having seen that there are three chairs in the spare room is my perceptual reason for believing that there are three chairs in the room. It is not easy to see what is supposed to be problematic about this notion (the fact that the locution 'see that' has more than one sense is not an objection to this account).

Furthermore, to speak of 'perceptual experience' need not be construed in a 'metaphysically loaded' sense such that these experiences are conceived as content-carrying intermediaries - as it were emissaries from the world that 'tell' us stuff (a conception that would rightly worry Travis and Williams). Rather, to speak of having a perceptual experience of something is just another way of saying that one is perceiving aspects or elements of one's immediate environment that are there to be perceived. Consequently, a veridical perceptual experience is one where one is made aware of a perceivable aspect of one's immediate environment, while in a non-veridical experience this is not the case, either because there is nothing suitable in the environment to perceive or because one draws the wrong conclusions from what one sees. For example, I see a barn façade and take it to be a barn. That is to say, sometimes our perceptual experiences can be taken at face value, i.e. license the judgement that 
something is the way it looks (in the good case), whereas sometimes the way things look is not a good guide to how they are (the bad case). Consequently, in order for perception to provide knowledge, we need to be in a situation that is both subjectively and objectively epistemically good (also see my response to Ranalli). In this respect, and if one wants to talk that way, the senses by themselves don't 'tell' us anything. But this, pace Williams, is perfectly compatible with holding that our perceiving that things are thus and so (which is not to be construed as 'bare' reliance on the senses, but rather requires the exercise of conceptual and recognitional capacities) in the good case gives one conclusive grounds for believing and, hence, knowing, that things really are thus and so (see also McDowell 2013, French 2019, and Longworth 2019).

\subsection{Wittgenstein on 'Objective Certainty'}

Williams is right that although my views have affinities with what has come to be known as 'hinge epistemology', my conception is also importantly different (...) in the sense that I hold that 'hinges' are neither known nor certain. If anything, Williams says, "this deepens the mystery. On any account of hinges, they 'stay put' and what is staying put, if not being certain?" (129). I agree, of course, that hinges must 'stay put', but disagree that this means that they must be certain. For if they are certain, this implies that they could also have been 'uncertain', had the world been otherwise, whereas Wittgenstein says that in respect to hinges "doubt is logically excluded" (OC §194).

Williams also takes issue with my distinction between a 'logical' (or grammatical) and an 'epistemic' sense of 'to know'. On my conception, where the expression of uncertainty is senseless, but no further grounds can be given, we are dealing with a purely 'logical' sense of 'to know' (OC §58-59); where it is possible to be wrong or uncertain, but reasons for correctness can be given, we are dealing with the ordinary, 'epistemic' use. Williams objects to this on the grounds that he believes that Wittgenstein does not make a hard and fast distinction between knowledge and certainty. To back this up, he quotes the following passage: "The difference between the concept of 'knowing' and the concept of 'being certain' isn't of any great importance at all, except where 'I know' is meant to mean: I can't be wrong..." (OC §8). Does this remark lend support to Williams' reading? Quite the reverse.

For what Wittgenstein is saying here is that the distinction between 'knowing' and 'being certain' is only of great importance in cases where 'I know' really means 'I can't be wrong'. Since, ordinarily, 'I know' does not mean 'I can't be wrong', we cannot, contra Williams, be dealing with an ordinary case of knowledge here. So, the passage in question really supports my reading that 'objective certainty' - cases where a doubt would be unintelligible (and, hence, one cannot be wrong) - is not to be assimilated with the ordinary sense of 
'to know', where it is always possible that, had things been otherwise, one might not have known the thing in question (and thus been wrong).

Knowledge, in other words, is bipolar for Wittgenstein. This applies both to cases of claims to know as well as to knowledge possession itself. According to Wittgenstein, it only makes sense to think one knows a proposition if it also makes sense to think one might not have known it. Where a doubt is unintelligible, so is ordinary knowledge-attribution. OC §10, which Williams himself quotes, makes this quite clear. But Williams gives the opening lines a particular spin, in order to make them fit his reading. Here is the passage:

I know that a sick man is lying there? Nonsense! I am sitting at his bedside, I am looking attentively into his face. - So, I don't know, then, that there is a sick man lying here? Neither the question nor the assertion makes sense. Any more than the assertion "I am here", which I might yet use at any moment, if suitable occasion presented itself...

Williams claims that this passage is only about the intelligibility of asserting a knowledge claim, not about the knowledge attribution itself, but this is clearly false. For the question 'I know that a sick man is lying here?' is not about a knowledge claim, but about whether I know that a sick man is lying there. When Wittgenstein says, "neither the question nor the assertion makes sense," what he is saying is that neither the knowledge claim, nor the question whether I know makes sense, thus showing that nothing much hangs for him on distinguishing between the assertability of knowledge and knowledge-attribution in this context. Where a doubt is unintelligible, neither knowledge attribution, nor claims to know make sense.

Williams goes on to ask, "Reporting my experience, I say, 'I knew right away that there was a sick man lying there'. I speak truly. How can this be if, as Schönbaumsfeld supposes, I didn't know at the time?" The 'right away' makes all the difference here. Seeing what looks like a human form huddled in blankets, I might not have known straight away that a sick man was lying there. I might have had to look more closely. This is what makes this case an ordinary case of knowing, where a doubt is perfectly intelligible and grounds can be given. I know that there is a sick man lying there, because I have taken a close enough look. But, from further away, I might have mistaken the man for a child.

Of course, none of these grounds-taking a closer look, switching on the light etc.-would be 'robust' enough to satisfy a sceptic. This is why Wittgenstein criticizes Moore's refutation attempt by appealing to things one knows. But Wittgenstein also thinks that the sceptic's doubt is an illusion of 
doubt - not because we know the things in question, but because such a doubt is itself unintelligible.

Williams comes quite close to saying something similar: "But where there is no room for doubt, there is no room for assuaging it by giving compelling grounds. In such cases there is knowledge, but nothing would be meant by saying 'I know'" (135-136). I agree with the first sentence, but not with the second. 'Objective certainty' is not a kind of certainty. In cases where something is 'objectively certain', it is impossible to be wrong (to make a 'mistake'), because 'being wrong' would constitute an "annihilation of all yardsticks" (OC §492) (it would be a 'move' for which there is no room in the game). Consequently, 'objective certainty' refers to the logical enabling conditions that make our practices possible, and Wittgenstein specifically contrasts such conditions with knowledge (and ordinary certainty).

There are two reasons for this. If I know something, it must be possible to provide some grounds for how or why I know. This does not, contra Williams, require attributing а Јтв conception of knowledge to Wittgenstein, as this is anachronistic and at odds with Wittgenstein's anti-theoretical bent, but it seems uncontroversial that Wittgenstein does think that knowledge requires justification of some kind: "Whether I know something depends on whether the evidence backs me up or contradicts me" (OC §504). Second, and as already mentioned, knowledge-attribution is bipolar for Wittgenstein. Since 'objective certainties' fail both of these conditions, they cannot be knowledge. The following passages make this clear:

"But can you doubt that you meant this?" - No; but neither can I be certain of it, know it. (Philosophical Investigations [PI] §679)

With the word "certain" we express complete conviction, the total absence of doubt, and thereby we seek to convince other people. That is subjective certainty.

But when is something objectively certain? When a mistake is not possible. But what kind of possibility is that? Mustn't mistake be logically excluded? (OC §194)

In respect to ordinary contingent empirical propositions, doubt cannot be logically excluded. Since, as Wittgenstein says, "It is always by favour of Nature that one knows something" (OC §505), non-inferential perceptual knowledge cannot, pace Williams, be an 'objective certainty'. Rather, once the Cartesian Picture has been dispelled and the Reasons Identity Thesis undermined, the possibility (and certainty) of perceptual knowledge will depend on whether 
I find myself in the good or the bad case. In the good case, my perceptual experiences will be factive and conclusive and thus provide me with certain perceptual knowledge, in the bad case they will not.

What stands fast, on the other hand, and is 'objectively certain', are the epistemic and rational principles that allow us to draw such distinctions in the first place. These are the logical enabling conditions, the 'hinges', that allow our epistemic practices to operate. Since such logical enabling conditions function like the constitutive rules of a game, they cannot be called into question without undermining the game as such. Does this imply that they are known or 'certain' in the ordinary sense? No. For this would imply that they could also be uncertain had the world been different. But this is impossible, as they constitute the background conditions that give meaning to our ordinary concepts. In this respect, the 'objective certainty' of the hinges is like what Wittgenstein says of the standard metre in Paris - just as the standard metre is neither imetre nor not $1 \mathrm{~m}$ long, so hinges are neither certain nor uncertain: "But this is, of course, not to ascribe any remarkable property to it [them], but only to mark its [their] peculiar role in the game of measuring with a metre-rule" (PI 50 ). ${ }^{2}$ In other words, just as the standard metre, hinges are instruments of the language (practice); they are not something that is represented, and, hence, known, but a "means of representation" (ibid.). For this reason, in radical sceptical contexts, 'I know I have two hands', is not really a specific empirical claim about hands, but rather conveys the "logical insight" (OC §59) that there is no such thing as a doubt in this case or that "The expression 'I do not know' makes no sense in this case" (OC §58). Since it follows from this, according to Wittgenstein, that "I know' makes no sense either" (OC $\S 58)$, Williams is wrong to think that Wittgenstein allows that objective certainty is a form of knowledge (but this, of course, is not a detraction).

\subsection{Introduction}

There is much that Moyal-Sharrock and I agree about. We agree that 'hinges' are logical enabling conditions that allow our epistemic (and non-epistemic) practices to operate. We also agree that radical scepticism is an illusion. Where we part company is regarding how best to conceive of what Wittgenstein means by 'objective certainty' - contexts where doubt is 'logically excluded'; where a 'mistake' is not possible. Moyal-Sharrock thinks 'objective certainty' is a kind of certainty: a non-epistemic, non-propositional type of 'basic belief'.

2 I take it to be a strength of my reading that the views that I attribute to Wittgenstein in OC square nicely with what he says in PI. 
I contend, on the other hand, that Wittgenstein rejects the whole idea that we need 'basic beliefs' at all. But before I go on to discuss this, I will say something about the question we also disagree about, namely, whether hinges can be expressed in propositions.

\subsection{The Propositionality of Hinges}

Moyal-Sharrock admits that the exegetical evidence in OC is not decisive on the question whether Wittgenstein is happy to speak of 'hinge propositions' or not. As I will show below, I think there is significant evidence that Wittgenstein does not endorse the view that Moyal-Sharrock attributes to him, but agree that more needs to be said than a "show of passages" (147). Moyal-Sharrock therefore proposes as a criterion for accepting some passages over others "their coherence with-their consistent and meaningful contribution to-Wittgenstein's ground-breaking account of hinge certainty: the account which puts an end to the regress problem of basic beliefs and to the coherence of radical scepticism" (148). If we take Moyal-Sharrock at her word, as a general exegetical principle this is clearly question-begging, as it already assumes the correctness of MoyalSharrock's own reading - that Wittgenstein is advancing an account of 'hinge certainty'. But if we leave that to one side and endorse only the second half of what she says, then her account is, on those grounds, not superior to mine: there is no regress problem on my reading, as the demand for global validation is incoherent and the radical sceptical problem turns out to be an illusion.

Furthermore, Moyal-Sharrock seems not to recognize that on my interpretation there is no 'hinge certainty' or 'basic belief' at all—only the logical exclusion of doubt - and therefore takes the following question as an objection to my view: "For, what would be gained by retaining propositionality other than a return to the standard view of basic beliefs as propositions, and therefore a return to square one in our attempts to solve the regress problem?" (148). As I have just said, there is no regress problem for Wittgenstein, as that presupposes that the global validation demand makes sense. Since incoherent questions can't be answered or solved, however, but only dissolved, Wittgenstein is not, on my interpretation, presenting a 'solution' to the regress problem. Neither are hinges, on my conception, 'basic beliefs', but logical enabling conditions (I dispute that they can be both). Consequently, contra Moyal-Sharrock, it is not the case that accepting the view that hinges can be expressed in propositions entails endorsing the 'standard view' that basic beliefs are certain judgements.

Nevertheless, the question 'what is the point of accepting the propositionality of hinges?' is a fair one, and here I would like to appeal to Wittgenstein:

What sort of proposition is: "What could a mistake here be like!" It would have to be a logical proposition. But it is a logic that is not used, because 
what it tells us is not taught by means of propositions. - It is a logical proposition; for it does describe the conceptual (linguistic) situation. (OC §51, translation emended).

Although we are not explicitly taught this 'logic' (rather we absorb it with other things we are taught), Wittgenstein seems fairly adamant here that there are logical propositions, and that what they do is describe the conceptual situation. Consequently, pace Moyal-Sharrock (2004: 42), Wittgenstein seems to reject his former pernicious, Tractarian essentialism about propositions-the notion that propositions can only be 'factual', where that means 'empirical'.

So, to answer the question, logical propositions are propositional because they describe the use of concepts. If we reject Tractarian essentialism, which I think it is obvious that later Wittgenstein does, ${ }^{3}$ we can be liberal about propositions: any sentence that expresses a thought (i.e. has conceptual content) can be a proposition: "Here one must, I believe, remember that the concept of 'proposition' is not a sharp one" (OC §320). ${ }^{4}$ Since grammatical rules have conceptual content, can be paraphrased, 'tell us' something etc., they are propositional. But unless one sticks to Tractarianism or already endorses MoyalSharrock's conception, this does not imply that grammatical rules are therefore empirical or factual or the expression of a judgement about the world.

Moyal-Sharrock's view, on the other hand, entails that all expressions of rules must be non-propositional, which seems odd. Since Moyal-Sharrock herself accepts that hinges can be articulated for heuristic purposes, she must believe that some conceptual content is being conveyed, so how is that done if not propositionally?

\subsection{Basic Beliefs and the Regress Problem}

From the way in which Moyal-Sharrock writes, one might think that she believes that there is a genuine regress problem and that Wittgenstein solved it

3 See, for example, PI §108, §134-137 (critique of the general form of the proposition).

4 Moyal-Sharrock mentions this quotation herself in her book Understanding Wittgenstein's On Certainty (2004: 35), but remarkably regards this as compatible with the Tractarian essentialism she attributes to later Wittgenstein - the view that a proposition must be descriptive and contingent (i.e. factual and empirical). Her reason for this is that she believes that Wittgenstein is only broad-minded about the "non-specialized use of the concept" (where the "specialized use" is the bipolar use). But why think that Wittgenstein is talking about the "non-specialized use" here (if he is even endorsing such a distinction, which seems doubtful)? In $\S 319$, he is talking about both logical and empirical propositions, thus apparently making a general point about propositions: "But wouldn't one have to say then, that there is no sharp boundary between propositions of logic and empirical propositions?" 
by presenting an enactive theory of hinge certainty. But such a notion not only flies in the face of Wittgenstein's anti-theoretical bent, ${ }^{5}$ it also assumes that Wittgenstein is accepting the terms of the debate-for example, that he agrees that there is a need for 'basic beliefs' of some kind — and then offers a novel way of conceiving of them. This strikes me as wrong-headed: it is Wittgenstein's aim to dissolve philosophical problems (PI §133) by showing that they arise because a picture (say the Cartesian one) has held us captive (PI §115); once the picture has been undermined, the house of cards (PI §118) collapses of its own accord.

Applied to OC what this means is that Wittgenstein wants to show that radical doubt is an illusion (OC §19). Since illusions or the problems generated by them cannot be refuted or solved, but only dissolved, no 'positive' response to scepticism is required. In other words, if radical doubt is an illusion, then so is the regress problem. Why? Because the regress problem is one ramification of radical doubt. If someone believes that there is a genuine radical sceptical problem, then one way of responding to that problem would be by appeal to something 'indubitable' (e.g., the Cogito, the 'certainty' of introspection, 'hinge certainty') that the sceptic cannot challenge. Conversely, if the radical sceptical problem is exposed as illusory, there is no need to appeal to 'basic beliefs' of whatever form, in order to solve it (or its ramifications). If, as Wittgenstein says, justification comes to an end (OC §192), then there is no 'final' justification or 'ground, ${ }^{6}$ be that epistemic, or, as on Moyal-Sharrock's conception, a non-epistemic, basic 'animal certainty'. Wittgenstein rejects the Cartesian Picture root and branch.

\section{4 'Standing Fast' versus 'Hinge Certainty'}

In response to my objection that hinges cannot both be grammatical rules (logical enabling conditions) as well as a know-how, ${ }^{7}$ Moyal-Sharrock appeals to a distinction between a "phenomenological" and a "categorical" or "epistemological" perspective on "basic certainty" (10-11). The phenomenological perspective constitutes "what it is like to be basically certain" (Moyal-Sharrock's emphasis), whereas the "categorical" or "epistemological" perspective concerns "the structure of rational evaluation" (Pritchard's words). I have qualms

5 See, for example, PI §109, PI §124-128.

6 Why is no 'final' justification needed? Because, as Wittgenstein says, the "foundation-walls are carried by the whole house" (OC $\$ 248)$.

7 Logical enabling conditions enable or make possible a know-how, but they are not themselves a know-how (whatever that could mean). 
about the former, because, in my view, there is no "what it is like" to be basically certain. Crucially, the absence of doubt does not imply the presence certainty.

Let me try to make clear what the exact bone of contention is here. So, I agree with Moyal-Sharrock and other 'hinge epistemologists' that hinges stand fast (that's what makes them hinges). This means that they are not up for grabs, not subject to question and in these respects technique-constituting and logically enabling. Furthermore, if one were to question or doubt them, this would not be a mistake for which there is room in the game, but an annihilation of all yardsticks (OC §492) (see also my response to Williams).

Does it follow from this that hinges are 'basic certainties'? No. If, in certain contexts, it is logically impossible to doubt, it is logically impossible to be certain too (even if this is a non-reflective, 'animal' certainty). For example, does my taking hold of a towel without any hesitation (OC \$510) show that I am 'basically certain' that the towel exists? Of course not. In the course of ordinary life such a strange idea would not even occur to me. I just use the towel. There is no question of its existing (or not existing), or its being certain that it exists. The absence of doubt does not manifest the presence of some pro-attitude even if, as Moyal-Sharrock contends, this is a non-reflective attitude. ${ }^{8}$

What is more, if this attitude is supposed to be like a faith or a trust, as Moyal-Sharrock also claims, then, surely, this must imply that hinges could, in principle, be up for grabs. Otherwise, what is the point of calling it a faith or a trust at all? One only trusts or has faith in contexts where that trust (or faith) could in principle be disappointed. If it is logically impossible for the trust to be disappointed, however, as in the case of 'hinge certainty', what is it that still makes this a trust? It doesn't appear to have anything in common with ordinary cases of trust or faith where one is always exposing oneself to the contingencies (and vicissitudes) of life.

8 In some of the passages that Moyal-Sharrock appeals to, in order to back up her reading, Wittgenstein is talking about ordinary certainty (not objective or 'hinge certainty'), and ordinary certainty is precisely what Wittgenstein reclaims from the sceptic (but ordinary certainty concerns matters that one could, in principle, also be uncertain about, if compelling grounds for this were given). So, for example, Moyal-Sharrock quotes: "If you tried to doubt everything you would not get as far as doubting anything. The game of doubting itself presupposes certainty" (OC §115). Here Wittgenstein is talking about being certain of ordinary facts, and what he is saying is that you cannot coherently doubt all facts at the same time. The previous paragraph makes this clear: "If you are not certain of any fact, you cannot be certain of the meaning of your words either" (OC §114). So, these passages do not support MoyalSharrock's contention that the word 'certainty' in these contexts means 'hinge certainty'. 
So, it seems that it is only if Cartesian global doubt continues to linger in our minds that we need basic certainty about what might otherwise be thought inherently doubtful. But once the Cartesian Picture has been undermined along with the Reasons Identity Thesis, there is no longer room for this kind of anxiety. Consequently, there is also no need for 'hinge certainty'. In other words, it is as Wittgenstein says in the Tractatus: "The solution of the problem ... is seen in the vanishing of the problem" (TLP 6.521).

\section{References}

DeRose, K. 1995. "Solving the Sceptical Problem," The Philosophical Review 104 (1): 1-52. Doyle, C., Milburn, J., and Pritchard, D. (eds.). 2019. New Issues in Epistemological Disjunctivism. London: Routledge.

Dretske, F. 1970. "Epistemic Operators," The Journal of Philosophy 67: 1007-1023.

Dretske, F. 2005. "The Case against Closure." In E. Sosa and M. Steup (eds.), Contemporary Debates in Epistemology, 13-26. Oxford: Blackwell.

French, C. 2019. "Epistemological Disjunctivism and its Representational Commitments." In Doyle, Milburn and Pritchard 2019, 169-193.

Kant, I. 1781/1929. The Critique of Pure Reason. Translated by Norman Kemp Smith . Basingstoke and London: Macmillan.

Longworth, G. 2019. "Settling a Question: Austin and Disjunctivism." In Doyle, Milburn and Pritchard 2019, 131-152.

McDowell, J. 2013. "Perceptual Experience: Both Contentful and Relational," European Journal of Philosophy 21 (1): 144-157.

Moyal-Sharrock, D. 2004. Understanding Wittgenstein's On Certainty. London: Macmillan.

Pritchard, D. 2012. Epistemological Disjunctivism. Oxford: Oxford University Press.

Wittgenstein, L. 1969. On Certainty. Edited by G.E.M. Anscombe and G.H. von Wright; translated by Anscombe and D. Paul . Oxford: Blackwell.

Wittgenstein, L. 20o9. Philosophical Investigations. Edited by P.M.S. Hacker and J. Schulte; translated by G.E.M. Anscombe , Hacker, and Schulte. Oxford: Blackwell. 